\title{
PREVALENCE OF ARTERIAL HYPERTENSION AND DIABETES MELLITUS AMONG CATARACT PATIENTS
}

\author{
V. Haykin ${ }^{1,2}$, Y. Zdravkov ${ }^{1,2}$, A. Isaeva ${ }^{3}$, S. Kostova ${ }^{1,2}$, Iv. Tanev ${ }^{1,2}$ \\ ${ }^{1}$ Clinic of Ophthalmology, University "Alexandrovska" Hospital, Sofia, Bulgaria \\ ${ }^{2}$ Department of Ophthalmology, Medical Faculty, Medical University - Sofia, Bulgaria \\ ${ }^{3}$ Department of Medical Chemistry and Biochemistry, Medical University - Sofia, Bulgaria
}

\begin{abstract}
Cataract is a leading cause for avoidable blindness. Age-related cataract is a multifactorial disease, affecting patients over 60 years old. Diabetes mellitus (DM), arterial hypertension (AH) or a combination of both are risk factors for developing a cataract.

The aim of the study is to evaluate the prevalence of DM and AH among cataract patients. After an informed consent, cataract patients were randomly chosen to participate in the study.

Diagnostic criteria for $\mathrm{AH}$ were defined as: systolic blood pressure higher than $140 \mathrm{mmHg}$, diastolic higher than $90 \mathrm{mmHg}$ and the usage of antihypertensive therapy. Diabetic patients (medical history of DM or reported usage of antidiabetic drugs) were divided in two groups: Type I DM if the patient is on insulin treatment before the age of 30 years, and Type II DM if the patient is on antidiabetic or insulin treatment after the age of 30 years.

A total of 126 cataract patients on average age of 66, 2 years participated the study. The youngest patient was a 29 years old female with type I DM and the oldest - 88 years old AH female. There were $63 \mathrm{AH}$ patients (50\%), 2 with type I DM (1.6\%), 6 with type II DM (4.8\%), 6 patients with AH and type I DM (4.8\%), and 11 patients with $\mathrm{AH}$ and type II DM (8.7\%). 38 patients had no DM or AH (30.2\%), among them 20 had no comorbidities.

Systemic $\mathrm{AH}$ and DM are non-infectious epidemic diseases. According to our study cataract formation in type I DM patients occurs earlier than in diabetes type II DM and hypertensive patients. Type II DM patients develop cataract earlier. We found no significant difference between the average ages of cataract surgery in $\mathrm{AH}$ patients and otherwise healthy patients (without comorbidities).

Hypertension was found in the majority of cataract patients $(50 \%)$ and prevalence of diabetes mellitus was $19.9 \%$. We can speculate that many cataract patients in Bulgaria do not undergo surgery due to their socioeconomic status. Hypertension and diabetes mellitus should be better controlled in order to decrease the incidence of visual loss caused by cataract.
\end{abstract}

Key words: cataract, risk factors

\section{INTRODUCTION}

Cataract is the leading cause for half of the avoidable blindness among elderly people worldwide. (1-5) Age-related cataract is a multifactorial disease, affecting mainly patients over the age of 60 years old. $(6,7)$

Investigating the risk factors for developing lens opacifications is of significant importance. (3) A lot of the risk factors for cataract are

*Correspondence to: Vasil Haykin, MD, 1 Georgi Sofiiski, Sofia, Bulgaria,vhaykin@gmail.com, +35929230234 clarified. Among them diabetes mellitus (DM) and arterial hypertension (AH) or the combination of both are the most prominent. $(3,7,8)$ Shui-Mei Lee et al. found that hypertension alternates ion transport through the lens capsule. As a result the secondary protein structures change, causing protein aggregation and lens opacification. (8) In order to lessen the socioeconomic burden of cataract, Park et al recommend $\mathrm{AH}$ to be better controlled. (5)

The development of cataract DM patients is connected to long-term hyperglycemia, 
fluctuations in glucose blood glucose levels and sorbitol accumulation in the lens. Sorbitol is produced through the polyol pathway after glucose is being reduced in a reaction catalyzed by the enzyme aldose reductase (AR). Higher concentrations of AR are found in LECs, undergoing osmotic and oxidative stress. $(9,10)$ Elevated levels of sorbitol in the lens and hyperglycemia cause hyperosmotic change, an influx of fluids, superoxide radicals and hydrogen peroxide generation, lens fiber degeneration, and formation of lens opacification.(3, 7, 8) Lens epithelial cells (LECs) apoptosis is observed as well. $(9,11)$

\section{Purpose}

The aim of our study is to evaluate the prevalence of $\mathrm{DM}$ and $\mathrm{AH}$ among cataract patients.

\section{MATERIALS AND METHODS}

After an informed consent, cataract patients of the Ophthalmology Clinic of University Hospital Alexandrovska were randomly chosen to participate in the study.

Diagnostic criteria for AH were defined as: systolic blood pressure higher than $140 \mathrm{mmHg}$,
HAYKIN V., et al. diastolic higher than $90 \mathrm{mmHg}$ and the usage of antihypertensive therapy. Diabetic patients (medical history of DM or reported usage of antidiabetic drugs) were divided in two groups: Type I DM if the patient is on insulin treatment before the age of 30 years, and Type II DM if the patient is on antidiabetic or insulin treatment after the age of 30 years.

\section{RESULTS}

A total of 126 cataract patients (43 males and 73 females) on average age of 66,2 years participated in this study. The youngest patient was a 29 years old female with type I DM and the eldest was an 88 years old $\mathrm{AH}$ female. There were $63 \mathrm{AH}$ patients, 2 patients with type I DM, 6 patients with type II DM, 6 patients with $\mathrm{AH}$ and type I DM and 11 patients with AH and type II DM (tabl. 1). 38 patients had no DM or $\mathrm{AH}$, among them 20 at average age of 68.15 years had no comorbidities. The average age of the patients with $\mathrm{AH}$ was 68.11 years, with type I DM was 55.42 years and with type II DM was 65.27. years (Figure 1). The prevalence of $\mathrm{AH}$ was $50 \%$, of type I DM was $1.6 \%$ and type II DM was $4.8 \%$ (Figure 2).

Table. 1 Prevalence of hypertension and diabetes among cataract patients

\begin{tabular}{|c|c|c|c|c|c|}
\hline & Males & Females & Mean age (y) & Total & $\begin{array}{c}\text { Percentage } \\
(\%)\end{array}$ \\
\hline AH & 21 & 42 & 68.9 & 63 & 50 \\
\hline Type I DM patients & 1 & 1 & 45.5 & 2 & 1.6 \\
\hline Type II DM patients & 4 & 2 & 60.6 & 6 & 4.8 \\
\hline AH and Type I DM patients & 5 & 0 & 59.4 & 5 & 4.8 \\
\hline AH and Type II DM patients & 6 & 5 & 66.7 & 11 & 8.7 \\
\hline Without AH or DM & 17 & 21 & 64.2 & 38 & 30.2 \\
\hline
\end{tabular}

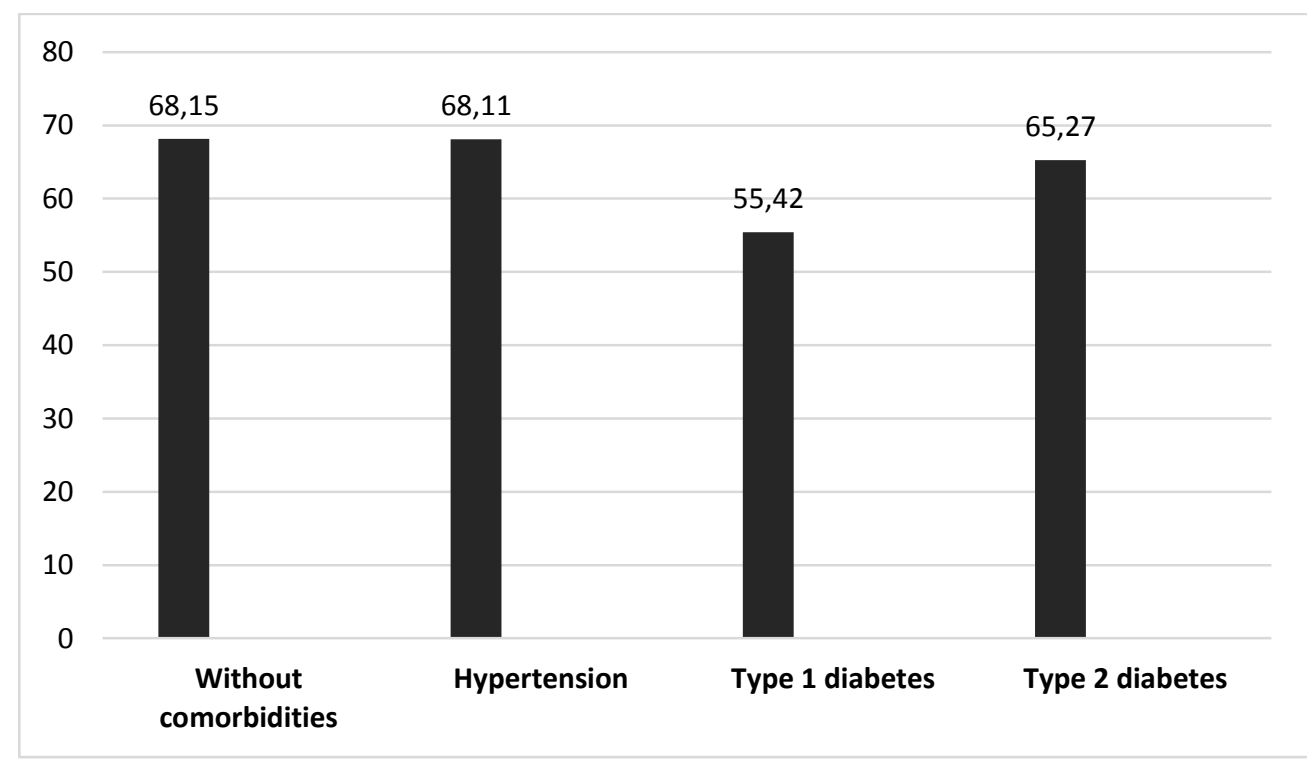

Figure 1. Average age (y) at surgery of hypertensive and diabetic patients and patients without comorbidities 


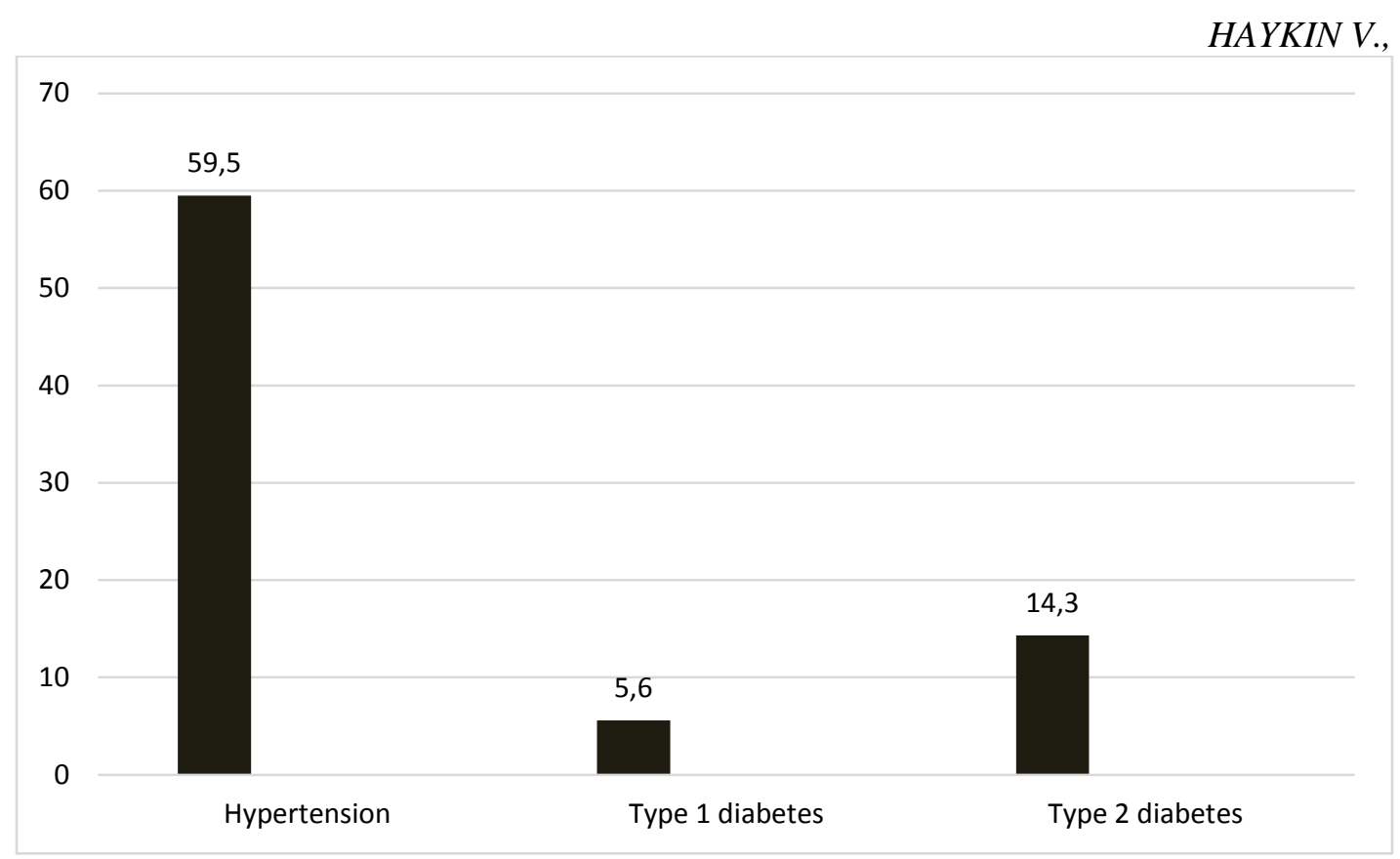

Figure 2. Prevalence (\%) of hypertension and diabetes among cataract patients

\section{DISCUSSION}

Systemic AH and DM are non-infectious epidemic diseases. Osmotic and oxidative stress is among the main pathogenetic mechanism for the formation of cataract.

According to our study cataract formation in type I DM patients occurs earlier than in diabetes type II DM and AH patients. Diabetes type II DM patients develop cataract earlier than the $\mathrm{AH}$ ones. We found no significant difference between the average age of cataract surgery in AH patients and otherwise healthy patients (without comorbidities).

$\mathrm{AH}$ is one of the most common diseases worldwide and its prevalence increases with age. $(3,7)$ There are several studies suggesting that $\mathrm{AH}$ increases the risk for developing a cataract. $(1,5,8,12)$ Xioaoning et al. analyzed 14 studies investigating the relationship between $\mathrm{AH}$ and cataract risk and find a significantly higher risk in hypertensive patients. (1) Furthermore, Sabanayagam et al. reported that patients with higher systolic blood pressure have a greater risk for developing cataract. $(1,13)$ Longer duration of $\mathrm{AH}$ is also reported as a risk factor. $(1,14)$

DM affects over 285 million people worldwide and this number is about to increase dramatically by the year 2030. (14) Earlier development and more rapid progression of cataract is observed in diabetic compared to nondiabetic patients. (14) As in cataract patients with hypertension, high economic burden is observed in diabetic cataract as well.

\section{CONCLUSION}

Hypertension was found in half of cataract patients $(50 \%)$. The prevalence of DM was found to be $19.9 \%$ among them. Cataract occurs earlier in DM patients. Although cataract surgery is widely available, many people suffering from cataract in Bulgaria do not undergo such surgery due to socioeconomic status. $\mathrm{AH}$ and $\mathrm{DM}$ are diseases that should be better controlled in order to lower the incidence of visual loss due to cataract and retinal vasculopathie.

\section{REFERENCES}

1. Yu X, Lyu D, Dong X, He J, Yao K. Hypertension and risk of cataract: A metaanalysis. PLoS ONE. 9(12):1-17, 2014.

2. Glynn RJ, Rosner B, Christen WG. Evaluation of risk factors for cataract types in a competing risks framework. Ophthalmic Epidemiology.16(2):98-106, 2009.

3. Leske MC, Wu S-Y, Hennis A, Connell AMS, Hyman L, Schachat A. Diabetes, hypertension, and central obesity as cataract risk factors in a black population. Ophthalmology. Jan;106(1):35-41, 1999.

4. Roodhooft JMJ. Leading causes of blindness worldwide. Bulletin de la Societe belge d'ophtalmologie. (283):19-25, 2002.

5. Park SJ, Lee JH, Kang SW, Hyon JY, Park KH. Cataract and Cataract Surgery: Nationwide Prevalence and Clinical Determinants. Journal of Korean Medical Science. 31(6):963, 20016. 
6. Nemet AY, Vinker S, Levartovsky S, Kaiserman I. Is cataract associated with cardiovascular morbidity? Eye.Mar;24:1352, 2010.

7. Pessoa R, Lira C, Nascimento MA, Eduardo C, Arieta L. Incidence of preoperative high blood pressure in cataract surgery among hypertensive and normotensive patients. 58(6):493-495, 2010.

8. Lee S-M, Lin S-Y, Li M-J, Liang R-C. Possible Mechanism of Exacerbating Cataract Formation in Cataractous Human Lens Capsules Induced by Systemic Hypertension or Glaucoma. Ophthalmic Research. 29(2):83-90, 1997.

9. Kumamoto Y, Takamura Y, Kubo E, Tsuzuki S, Akagi Y. Epithelial cell density in cataractous lenses of patients with diabetes: Association with erythrocyte aldose reductase. Experimental Eye Research. Sep;85(3):393-9, 2007.

10.Srivastava SK, Ramana KV, Bhatnagar A. Role of Aldose Reductase and Oxidative Damage in Diabetes and the Consequent Potential for Therapeutic Options.
Endocrine Reviews. May;26(3):380-92, 2005.

11.Pollreisz A, Schmidt-Erfurth U. Diabetic Cataract-Pathogenesis, Epidemiology and Treatment. Journal of Ophthalmology. 2010:1-8, 2010.

12.Phaswana-Mafuya N, Peltzer K, Crampin A, Ahame E, Sokhela Z. Prevalence of Self-Reported Diagnosed Cataract and Associated Risk Factors among Elderly South Africans. Int J Environ Res Public Health [Internet]. Dec [cited 2019 Feb 12];14(12), 2017. Available from: https://www.ncbi.nlm.nih.gov/pmc/articles/ PMC5750941/

13.Sabanayagam C, Wang JJ, Mitchell P, Tan AG, Tai ES, Aung T, et al. Metabolic Syndrome Components and Age-Related Cataract: The Singapore Malay Eye Study. Investigative Opthalmology \& Visual Science. Apr 14;52(5):2397, 2011.

14.Delcourt C, Carrière I, Delage M, Descomps B, Cristol J-P, Papoz L. Associations of cataract with antioxidant enzymes and other risk factors. Ophthalmology. Dec;110(12):2318-26, 2003. 